\title{
Estimativa do volume e da pressão de turgescência do estômato de vicia faba ao longo do dia
}

\author{
Estimation of the volume and turgor pressure stomatal of vicia faba along day
}

\author{
Vinícius Marcio Rodrigues Pereira ${ }^{1 *}$, Denilton Carlos $\mathrm{Gaio}^{2}$, Iramaia Jorge Cabral de Paulo ${ }^{3}$, \\ Leone Francisco Amorim Curado e José de Souza Nogueira ${ }^{5}$ \\ 1,2,3,4,5 Programa de Pós Graduação em Física Ambiental - Instituto de Física - Universidade Federal de Mato \\ Grosso, Mato Grosso, Brasil
}

\begin{abstract}
Resumo
Os estômatos controlam a saída de água da planta e esse controle depende da variação do volume estomático, que por sua vez depende da variação da pressão de turgescência estomática. Dessa forma, o presente trabalho teve como objetivo estimar o volume e a pressão de turgescência do par de células guarda estomáticas da Vicia faba ao longo do dia. Foram utilizados os parâmetros biofísicos do estômato da Vicia faba encontrados na literatura e a equação de Van't Hoff para estimar a pressão osmótica gerada pelos solutos osmoticamente ativos (potássio, sacarose e cloro). Os valores resultantes estão de acordo com a literatura e podem ser utilizados em simulações, como, por exemplo, modelagem da transpiração foliar a partir da equação de Weyers e Meidner (1990).
\end{abstract}

Palavras-chave: Vicia faba. Estômato. Equação de Van't Hoff. Pressão osmótica. Solutos osmoticamente ativos.

\begin{abstract}
The stomata control the plant water outlet and this control depends on the stomatic volume variation which in turn depends on the variation of the stomatic turgor pressure. Therefore, the aim of this study was to estimate the volume and turgor pressure of the stomata Vicia faba through the day. The biophysical parameters of the stomata Vicia faba found in the literature and Van't Hoff equation were utilized to estimate the osmotic pressure generated by the osmotically active solutes (potassium, chloro and sucrose). The resulting values are in agreement with literature and can be used in simulations, such as the study of leaf transpiration through the equation Weyers and Meidner (1990).
\end{abstract}

Keywords: Vicia faba. Stomata. Van't Hoff Equation. Osmotic pressure. Osmotically active solutes. 


\section{Introdução}

$\mathrm{A}$ s plantas vasculares têm suas raízes inseridas no solo absorvendo água e nutrientes e, as folhas estão sujeitas principalmente à ação da atmosfera, radiação solar e do vento, obrigando-as a transpirar incessantemente. De maneira geral, elas absorvem aproximadamente 500 gramas de água para cada grama de $\mathrm{CO}_{2}$ fixado pela fotossíntese. Nas folhas, encontram-se os estômatos, estruturas que, quando abertas, permitem o fluxo de $\mathrm{CO}_{2}$ para os cloroplastos e de água para a atmosfera (REICHARDT; TIMM, 2004). Quase toda a água absorvida pelas raízes é liberada para o ar através das folhas como vapor d'água pelo processo de transpiração (RAVEN, 2001).

Para manter o balanço entre a perda de água e suas necessidades gasosas, as plantas possuem um sofisticado sistema de controle estomático. Esses estômatos, cercados por células epidérmicas, são formados por células guarda que se abrem e se fecham em resposta a sinais ambientais ou fisiológicos (RAVEN, 2001). Segundo Shimazaki et al. (2007), a luz, principalmente azul e vermelha, é o sinal ambiental mais proeminente na osmorregulação da célula-guarda, induzindo o movimento estomático. Ela desencadeia os processos de captação de íons potássio $(\mathrm{K}+)$ e produção de açúcares nas células guarda, no entanto, ainda existem dúvidas entre os pesquisadores sobre como a luz promove esse processo (ROELFSEMA et al., 2001).

Quando a luz azul incide sobre a membrana plasmática do estômato, é ativado um processo de extrusão de prótons $\left(\mathrm{H}^{+}\right)$por meio da bomba $\mathrm{H}^{+}$ATPase, hiperpolarizando a membrana (ASSMANN, 1985; WU, 1995 e GOH, 2002). Para compensar a falta de $\mathrm{H}^{+}$, é aberto um canal para entrada de íons potássio $\left(\mathrm{K}^{+}\right)$chamado bomba de potássio (SHIMAZAKI et al., 2007). Para contrabalancear a carga positiva devido ao acúmulo de potássio, ocorre a entrada de íons cloro $\left(\mathrm{Cl}^{-}\right)$(ROELFSEMA; HEDRIC, 2005). Esses solutos elevam o potencial osmótico, resultando em uma diminuição no potencial hídrico e na subsequente absorção de água. Em consequência, aumentam a pressão osmótica da célula e o seu volume, com isso, alarga-se a abertura do estômato.
A luz vermelha é absorvida pelos cloroplastos da célula guarda e do mesófilo. Os cloroplastos fornecem ATP (energia) para o funcionamento da bomba $\mathrm{H}^{+}$ATPase e da bomba de potássio e auxiliam na síntese do malato-2 (OLSEN, 2002). Já os cloroplastos do mesófilo fixam $\mathrm{CO}_{2}$ (realizam fotossíntese), o que reduz a sua concentração do $\mathrm{CO}_{2}$ (ROELFSEMA; HEDRIC, 2005). Essa redução ativa um processo que mantém a membrana hiperpolarizada, mantendo, portanto, a bomba de potássio em funcionamento (SHIMAZAKI et al., 2007).

Os diagramas esquemáticos para compreender a osmorregulação, ou seja, como os solutos se acumulam na célula-guarda e variam o seu volume em função da entrada ou saída de água, foram descritos por Talbott e Zeiger (1998); Vavasseur e Raghavendra (2004); Shimazaki et al. (2007) e Lawson (2009).

Segundo Lang et al. (1969), a oscilação do movimento estomático vem sendo observado desde 1920. Gaio (2011) desenvolveu uma modelagem do funcionamento do estômato em função da pressão de turgescência das células guarda com base no modelo fisiológico de Buckley (2005), sem introduzir, todavia, a modelagem da osmorregulação. Porém, não foram esgotados os estudos nessa área, pois até hoje existem teorias que diferem entre si quando se trata do movimento estomático. Por exemplo, Tallman e Zeiger (1988); Talbott e Zeiger (1998) verificaram que o potássio $(\mathrm{K}+)$ é o principal soluto osmoticamente ativo no início do dia. Já Poffenroth et al. (1992) observaram que a sacarose também aumenta rapidamente de manhã.

Dessa forma, o objetivo deste estudo foi estimar o volume e a pressão de turgescência das células-guarda ao longo do dia a partir do tratamento fisiológico da osmorregulação por meio dos valores experimentais presentes na literatura para a folha intacta da Vicia faba.

\section{MATERIAL E MÉTODOS}

Para a realização deste estudo, foram utilizados parâmetros biofísicos, estimados com base na literatura, do estômato da Vicia faba que são apresentados na Tabela 1

Tabela 1 - Parâmetros biofísicos do estômato da Vicia faba

\begin{tabular}{cccc}
\hline & Estômato fechado & Estômato aberto & Experimento-modelo \\
\hline Abertura média $^{(\mathrm{a})}$ & $1.26 \mu \mathrm{m}$ & $12.89 \mu \mathrm{m}$ & Pereira, 2013 \\
Volume $^{(\mathrm{b})}$ & $3.5 \mathrm{pl}$ & $5 \mathrm{pl}$ & Shope et al., 2003 \\
Turgescência $^{(\mathrm{c})}$ & $1 \mathrm{MPa}$ & $4.5 \mathrm{MPa}$ & Franks et al., 1998 \\
Teor de K$^{+}$(d) & $0.1 \mathrm{pmol}$ & $2.1 \mathrm{pmol}$ & Roelfsema; Hedric, 2005 \\
Teor de Sacarose $^{(\mathrm{e})}$ & $0.2 \mathrm{pmol}$ & $1.55 \mathrm{pmol}$ & Talbott; Zeiger, 1996 \\
${\text { Teor de } \mathrm{Cl}^{-}}^{(\mathrm{f})}$ & $0.2 \mathrm{pmol}$ & $1 \mathrm{pmol}$ & Roelfsema; Hedric, 2005 \\
\hline
\end{tabular}


Tabela 2. Dados da abertura estomática média ao longo do dia e dos teores de cada soluto ao longo do dia. Os teores dos solutos (potássio, sacarose e cloro) ao longo do dia foram digitalizados dos gráficos obtidos experimentalmente por Talbott e Zeiger (1996), baseando-se nos parâmetros da Tabela 1

\begin{tabular}{ccccc}
\hline $\begin{array}{c}\text { Hora do } \\
\text { Dia }\end{array}$ & $\begin{array}{c}\text { Abertura média } \\
(\boldsymbol{\mu} \mathrm{m})\end{array}$ & $\begin{array}{c}\text { Teor de potássio } \\
(\mathrm{pmol})\end{array}$ & $\begin{array}{c}\text { Teor de sacarose } \\
(\mathrm{pmol})\end{array}$ & $\begin{array}{c}\text { Teor de cloro } \\
(\mathrm{pmol})\end{array}$ \\
\hline 5 & 1.26 & 0.10 & 0.20 & 0.2 \\
6 & 2.54 & 0.15 & 0.20 & 0.22 \\
7 & 3.22 & 0.12 & 0.22 & 0.33 \\
8 & 5.32 & 0.45 & 0.22 & 0.46 \\
9 & 8.26 & 1.18 & 0.34 & 0.59 \\
10 & 10.9 & 2.10 & 0.74 & 0.78 \\
11 & 9.14 & 0.32 & 0.89 & 1.00 \\
12 & 11.57 & 0.75 & 0.97 & 0.88 \\
13 & 12.89 & 0.90 & 1.55 & 0.77 \\
14 & 10.53 & 0.90 & 1.23 & 0.77 \\
15 & 8.71 & 1.04 & 0.38 & 0.75 \\
16 & 7.68 & 0.57 & 0.28 & 0.67 \\
17 & 6.39 & 0.38 & 0.33 & 0.55 \\
18 & 4.81 & 0.38 & 0.37 & 0.27 \\
\hline
\end{tabular}

Os gráficos dos teores de potássio, de sacarose e de cloro ao longo do dia, encontrados nos trabalhos experimentais de Talbott e Zeiger (1996), foram digitalizados com intervalo de 1 hora entre cada valor, conforme Tabela 2. Neste estudo, o teor de potássio ao longo do dia, encontrado por Talbott e Zeiger (1996), expresso em porcentagem em relação aos limites de fechamento e abertura do estômato e o teor de cloro ao longo do dia, expresso em conteúdo de cloro em relação aos limites de fechamento e abertura do estômato, foram convertidos em valores absolutos a partir dos dados da Tabela 1 linhas ${ }^{(d)} \mathrm{e}^{(\mathrm{f})}$, correspondendo aos teores de $\mathrm{K}^{+}$e de $\mathrm{Cl}^{-}$, respectivamente.

Considerando que a abertura estomática varia linearmente em função do volume das células guarda (FRANKS, 2003), estabeleceu-se uma relação linear entre os limites máximos e mínimos da abertura estomática média Tabela 1 linha ${ }^{\text {(a) }}$ e do volume estomático Tabela 1 linha ${ }^{(b)}$ chegando-se à equação 1 :

$$
V_{e}=\frac{38.815+\left(1.5 a e_{m}\right)}{11.63}
$$

em que,

$V_{\mathrm{e}}$ é o volume estimado do par de células guarda em picolitros ( $\mathrm{pl}$ ) e $(\mu \mathrm{m})$.

$a e_{m}$ é a abertura estomática média em micrômetros

Segundo a relação de Van't Hoff, a pressão osmótica de uma solução depende da concentração dos solutos em questão e da temperatura na qual se encontram.

$$
\Pi_{s}=R T \sum_{j} c_{j}
$$

em que,

$\Pi_{S}$ é a pressão osmótica da célula (MPa),

$\mathrm{R}$ é a constante dos gases perfeitos $\left(8.314 \mathrm{E}^{-3} \mathrm{MPa}\right.$. pl.pmol $\left.{ }^{-1} \cdot \mathrm{K}^{-1}\right)$,

T é a temperatura absoluta da célula (em média 298 K).

Nesta expressão, $c_{j}$ é a concentração de cada soluto na célula (pmol/pl)

$$
c_{j}=\frac{n_{j}}{V}
$$

em que é o teor de soluto de cada um dos componentes da mistura (pmol) e V é o volume da célula-guarda (pl).

Assim, estima-se o volume estomático ao longo do dia utilizando a relação 1 com os valores da Tabela 1 e 2 e a pressão osmótica gerada por soluto utilizando a relação 3 com os valores da Tabela 2 e do volume estomático.

\section{RESULTADOS E DISCUSSÃO}

O volume estimado, por meio da relação 1 , do par de células guarda da Vicia faba variando entre 3.5 e 5 picolitros (pl) ao longo do dia está mapeado na Figura 1. 


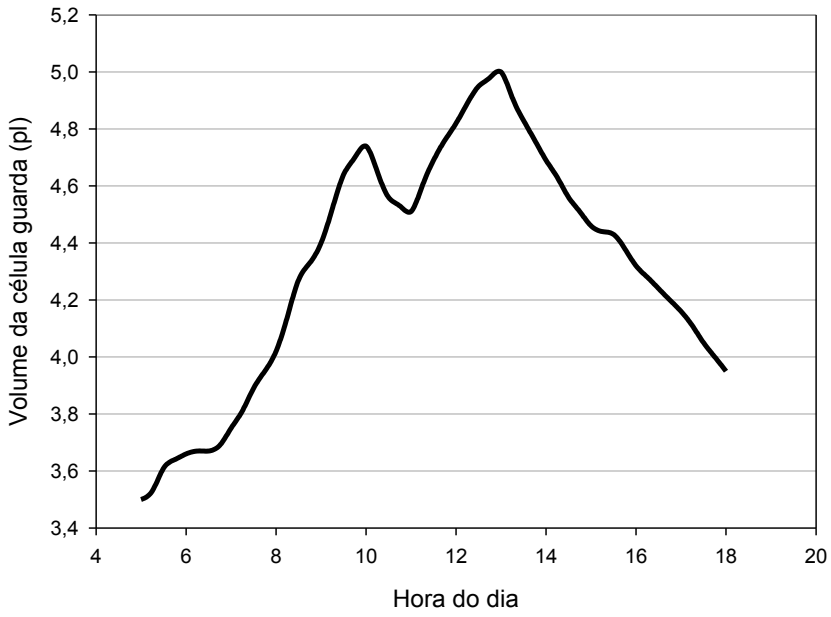

Figura 1 - Estimativa do volume da célula guarda da Vicia faba ao longo do dia, obtida por meio da equação 1

A estimativa da pressão osmótica, devida ao teor de potássio, no par de células guarda da Vicia faba ao longo do dia (Figura 3) foi obtida a partir da equação 2, considerando os teores de potássio fornecidos pela Tabela 2 e o volume médio da célula guarda dado pela Figura 1.

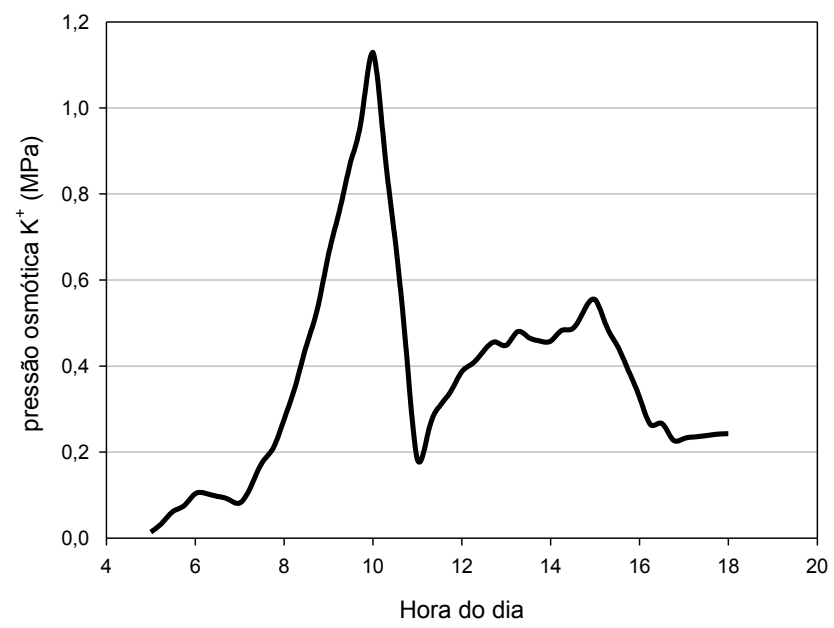

Figura 2 - Estimativa da pressão osmótica no par de células guarda da Vicia faba, gerada pelo soluto potássio utilizando a equação 2 considerando os dados da Tabela 2 e Figura 1

Na Figura 2, a pressão osmótica estimada no par de células guarda da Vicia faba teve valor nulo às $05 \mathrm{~h} 00 \mathrm{~min}$. A partir das 07h00min houve um rápido aumento na pressão osmótica, que segundo Shimazaki et al. (2007) pode ser explicado pelo fato do estômato começar a receber radiação solar e ativar o processo de extrusão de $\mathrm{H}^{+}$e entrada de íons potássio. $\mathrm{O}$ pico de $1.2 \mathrm{MPa}$ ocorreu aproximadamente às 10:00h, coincidindo com o primeiro pico de volume da Figura 1. Um segundo pico ocorreu às $15 \mathrm{~h} 00 \mathrm{~min}$, com $0.55 \mathrm{MPa}$. O rápido aumento da pressão osmótica produzida pelo soluto potássio influenciou o aumento do volume estomático no período matutino (FRANKS et al., 2001). Foi obser- vado que ocorreu uma queda da pressão osmótica às 11h00min, que de acordo com Talbott e Zeiger (1998), é ligado à mudança de mecanismo osmótico, pois durante a manhã o $\mathrm{K}^{+}$acumulado é utilizado para uma rápida abertura do estômato, após isso, a sacarose sustenta a abertura no período vespertino.

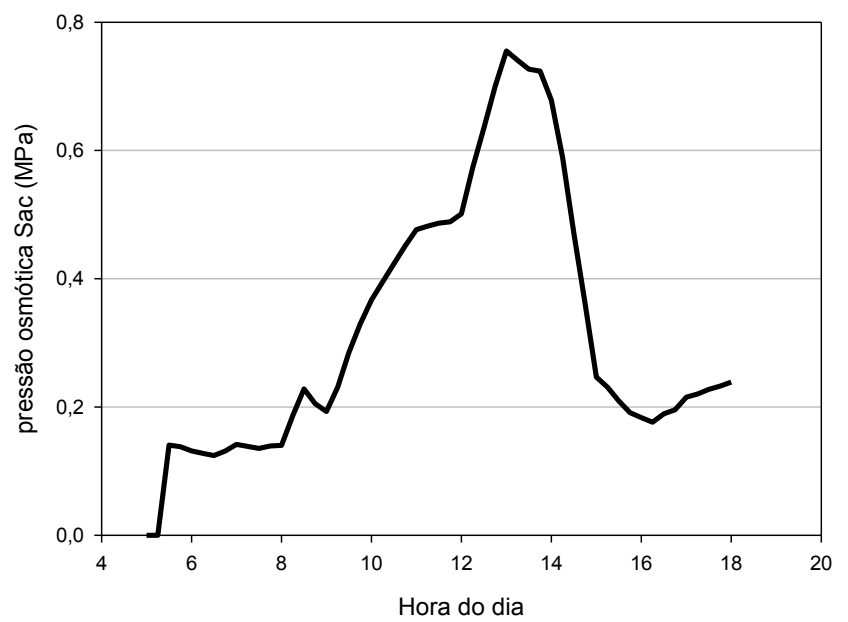

Figura 3 - Estimativa da pressão osmótica no par de células guarda da Vicia faba, gerada pelo soluto sacarose utilizando a equação 2 considerando os dados da Tabela 2 e Figura 1

Na Figura 3, a pressão osmótica gerada pelo soluto sacarose no par de células guarda da Vicia faba teve valor nulo às 05h00min. A partir das 09h00min houve um aumento na pressão osmótica, que culminou às $13 \mathrm{~h} 00 \mathrm{~min}$ com valor de $0.75 \mathrm{MPa}$ e, após esse horário, começou a diminuir. A sacarose tem principal atuação no período vespertino devido à alta produção pela fotossíntese e degradação de açúcar como demonstrado experimentalmente por Talbott e Zeiger (1996); Ritte et al. (1999).

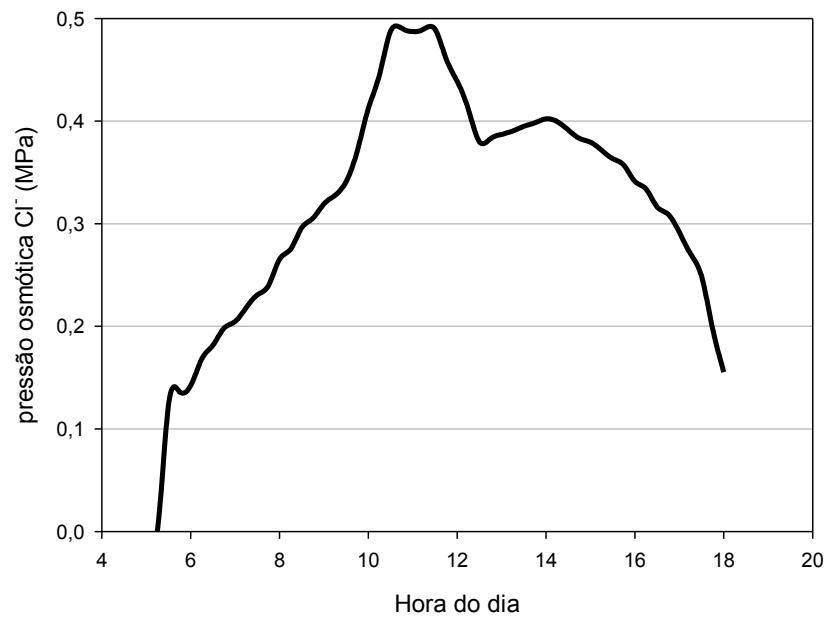

Figura 4 - Estimativa da pressão osmótica no par de células guarda da Vicia faba, gerada pelo soluto cloro utilizando a equação 2 considerando os dados da Tabela 2 e Figura 1 
Conforme apresentado na Figura 4, a pressão osmótica gerada pelo soluto cloro da célula guarda da Vicia faba teve valor nulo às $05 \mathrm{~h} 00 \mathrm{~min}$. A partir das $05 \mathrm{~h} 30 \mathrm{~min}$, houve rápido aumento na pressão osmótica devido ao fato de o soluto cloro ser transportado da vizinhança da célula guarda com o objetivo de contrabalancear a carga negativa causada pelo acúmulo do soluto potássio (RASCHKE; SCHNABL, 1978). O pico de 0,49 Mpa ocorreu aproximadamente às $10 \mathrm{~h} 30 \mathrm{~min}$, próximo ao primeiro pico da Figura 2. Um segundo pico ocorreu aproximadamente às $14 \mathrm{~h} 00 \mathrm{~min}$, também próximo ao segundo pico da Figura 2. Outros solutos também acompanham o cloro (ROELFSEMA; HEDRIC, 2005), porém não foram estudados neste trabalho.

Uma estimativa da pressão osmótica total (Figura 5) foi obtida por meio da soma das pressões devidas aos teores dos três solutos estudados (Figuras 2, 3 e 4), no par de células guarda da Vicia faba. ao longo do dia.

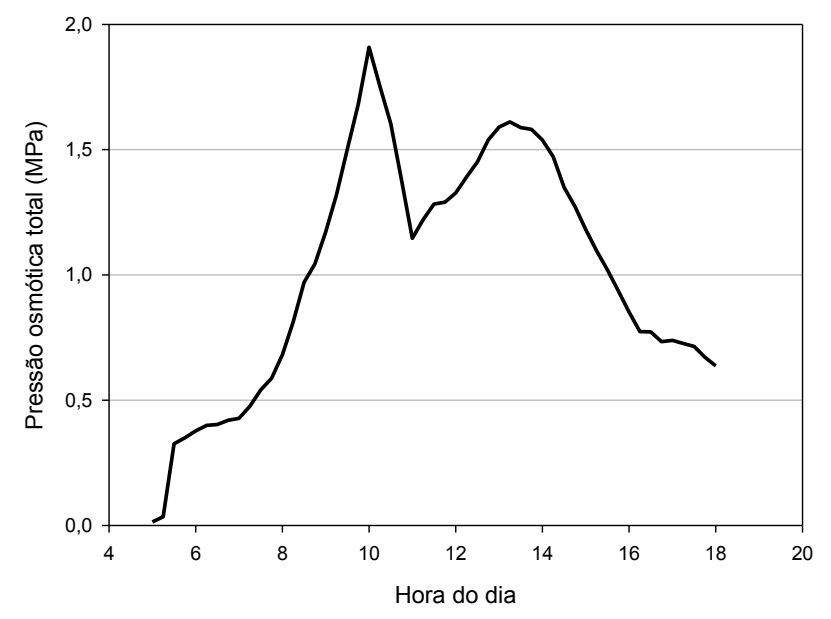

Figura 5- Estimativa da pressão osmótica total do par de células guarda do estômato da Vicia faba ao longo do dia, resultante da soma das curvas das Figuras 2, 3 e 4

Na Figura 1, existem dois picos referentes ao máximo volume da célula guarda, semelhante ao da Figura 5. Os dois picos podem ser explicados pelas duas fases distintas da osmoregulação, que ocorrem no movimento estomático. Segundo Talbott e Zeiger (1996), durante a primeira fase (matutino) a abertura estomática está relacionada à absorção de íons potássio e, em menor escala, ao acúmulo de sacarose. Na segunda fase (vespertino), a absorção de íons potássio diminui e o acúmulo de sacarose se acentua. Roelfsema e Hedric (2005); Shimazaki et al. (2007) também discutem o movimento estomático relacionando-os com o transporte de solutos ao longo do dia.

A pressão osmótica ou de turgescência máxima do estômato obtida na estimativa (Figura 5) foi $1.91 \mathrm{MPa}$. No entanto, segundo Franks et al. (1998), mesmo com o estômato fechado, a célula guarda possui uma pressão de turgescência mínima de $1 \mathrm{MPa}$ que deve ser considerada, totalizando aproximadamente $2.91 \mathrm{Mpa}$. Roelfse- ma e Hedric (2005), considerando que o par de células guarda do estômato da Vicia faba teriam um volume de $4 \mathrm{pl}$ e acumulariam cerca de 2 pmol de íons potássio, 1 pmol de $\mathrm{Cl}^{-}$e 1 pmol de malato-2, estimaram a pressão de turgescência máxima do estômato de Vicia faba por meio da equação 2 em aproximadamente $3.4 \mathrm{MPa}$.

Em ambos os estudos citados anteriormente, a pressão de turgescência foi menor que o valor experimental (4.5 MPa) obtido por Franks et al. (1998). Isso pode ter ocorrido por uma subestimativa da concentração de solutos. Segundo Humble e Hsiao (1969), a abertura estomática pode ser sustentada também por outros cátions monovalentes como $\mathrm{Rb}^{+}, \mathrm{Li}^{+}, \mathrm{Cs}^{+}$e $\mathrm{Na}^{+}$e malato ${ }^{-2}$.

\section{CONCLUSÃO}

Observou-se que a pressão de turgescência do estômato da Vicia faba calculada pelo método empregado neste estudo foi satisfatório, com valores próximos aos dos métodos experimentais encontrados na literatura.

A estimativa da pressão de turgescência ao longo dia é importante para utilizar em simulações como, por exemplo, a do fluxo hídrico estomático proposto por Gaio (2011), contribuindo para modelagem estomática.

Considera-se importante que pesquisas para estimar a pressão de turgescência estomática sejam incentivadas, principalmente a realização de novos experimentos que permitam simulações in silico a fim de que se possa compreender melhor a dinâmica estomática contribuindo para a modelagem ambiental.

\section{AGRADECIMENTOS}

Os autores agradecem ao Conselho Nacional de Desenvolvimento Científico e Tecnológico (CNPQ) pelo apoio financeiro e ao Programa de Pós Graduação em Física Ambiental (PPGFA) da Universidade Federal de Mato Grosso pelo incentivo à pesquisa.

\section{REFERÊNCIAS}

ASSMANN, S.M. et al. Blue light activates electrogenic ion pumping in guard cell protoplasts of Vicia faba. Nature, vol. 318, p. 285 - 287, 1985.

BUCKLEY, T.N. The control of stomata by water balance. Tansley Rewiew. New Phytologist, vol.168, p. 275-292, 2005.

FRANKS, P.J. et al. A study of stomatal mechanics using the cell pressure probe. Plant, Cell and Environment, vol. 21, p. $94-100,1998$. 
FRANKS, P.J. Use of the pressure probe in studies of stomatal function. Journal of Experimental Botany, vol. 54, p. 1495 - 1504, 2003.

GAIO, D.C. Análogo elétrico da dinâmica hídrica em plantas vasculares. Cuiabá. 2011. 104 f. Tese (Doutorado em Física Ambiental), Instituto de Física, Universidade Federal de Mato Grosso.

GOH, C.H., et al., Parallel recordings of photosynthetic electron transport and $\mathrm{K}^{+}$-channel activity in single guard cells. Plant Journal, vol. 32, p. 623 - 630, 2002.

HUMBLE G.D., HSIAO T.C. Specific requirement of potassium for light-activated opening of stomata in epidermal strips. Plant Physiology, vol. 44(2), p. 230-234, 1969.

LANG, A. et al. Leaf Water Balance During Oscillation of Stomatal Aperture. Plant Physiology, vol. 44, p. 826-830, 1969.

LAWSON, T. Guard cell photosynthesis and stomatal function. New Phytologist, vol. 181, p. 13 - 34, 2009.

OLSEN, R.L et al. Red light activates a chloroplastdependent ion uptake mechanism for stomatal opening under reduced $\mathrm{CO}_{2}$ concentrations in Vicia faba spp. New Phytologist, vol. 153. p. 497 - 508, 2002.

PEREIRA, V.M.R.; Análogo Elétrico da Pressão de Turgescência em Células Guarda de Vicia Faba: Modelo Científico e Conceitual. Cuiabá. 66 f. Dissertação (Mestrado em Física Ambiental), Instituto de Física, Universidade Federal de Mato Grosso. 2013.

POFFENROTH M, et al. Sugar concentrations in guard cells of Vicia faba illuminated with red or blue light. Plant Physiology, vol. 98, p. 1460-1471, 1992.

RASCHKE K, SCHNABL H. Availability of chloride affects the balance between potassium chloride and potassium malate in guard cells of Vicia faba L. Plant Physiology, vol. 62, p. 84-87, 1978.

RAVEN, P.H., EVERT, R.F. \& EICHHORN, S.E. Biologia Vegetal. $6^{a}$ edição. Rio de Janeiro: Guanabara Koogan S. A, 968p., 2001.

REICHARDT, K. \& TIMM, L. C. Solo, Planta e Atmosfera. Conceitos, processos e aplicações. 1. Barueri: Editora Manole Ltda, 476p., 2004.

RITTE G, ROSENFELD J, ROHRIG K, RASCHKE K. Rates of sugar uptake by guard cell protoplasts of Pisum sativum L. related to the solute requirement for stomatal opening. Plant Physiology, vol. 121, p. 647-655, 1999.
ROELFSEMA, M.R.G \& HEDRIC, R. In the light of stomatal opening: new insights into 'the Watergate'. New Phytologist, vol. 167, p. 665 - 691, 2005.

ROELFSEMA, M.R.G., STEINMEYER R., STAAL M., HEDRICH R. Single guard cell recordings in intact plants: light-induced hyperpolarization of the plasma membrane. The Plant Journal, vol. 26, p. 1-13, 2001.

SHIMAZAKI, K. et al. Light Regulation of Stomatal Movement. Plant Biology, vol. 58, p. 219 - 247, 2007.

SHOPE, J. C. et al. Changes in Surface Area of Intact Guard Cells Are Correlated with Membrane Internalization. Plant Physiology, vol. 133, p. 1314 - 1321, 2003.

TALBOTT, L.D. \& ZEIGER, E. Central Roles for Potassium and Sucrose in Guard-Cell Osmoregulation. Plant Physiology, vol. 111, p. 1051 - 1057, 1996.

TALBOTT, L.D. \& ZEIGER, E. The role of sucrose in guard cell osmoregulation. Journal of Experimental Botany, vol. 49, p. 329 - 337, 1998.

TALLMAN, G. \& ZEIGER E. Light quality and osmoregulation in Viciaguard cells: Evidence for involvement of three metabolic pathways. Plant Physiology, vol. 88, p. 887-895, 1988.

VAVASSEUR, A. \& RAGHAVENDRA, A. S. Guard cell metabolism and $\mathrm{CO}$ sensing. New Phytologist, vol. 165, p. $665-682,2004$.

WEYERS, J.D.B. \& H. MEIDNER “Methods in Stomatal Research". Essex: Longman Scientific and Technical. 1990.

WU, W.H., ASSMANN, S. M. Is ATP required for K channel activation in Vicia guard cells? Plant Physiology, vol. 107, p. 101 - 109, 1995. 